\title{
The Prevalence, Correlates and Functions of Non-Suicidal Self-Injury in Vietnamese Adolescents
}

\author{
Truc Thanh Thai ${ }^{\prime}{ }^{1}$ \\ Mairwen $\mathrm{K}$ Jones ${ }^{2}$ \\ Thao Phuong Nguyen' \\ Thao Van Pham ${ }^{1}$ \\ $\mathrm{Han} \mathrm{Hy}$ Thi Bui ${ }^{3}$ \\ Loan Xuan Kim' \\ Tap Van Nguyen (1D)
}

'Faculty of Public Health, University of Medicine and Pharmacy at Ho Chi Minh City, Ho Chi Minh City Vietnam; ${ }^{2}$ Faculty of Medicine \& Health, The University of Sydney, Sydney, New South Wales, Australia; ${ }^{3}$ Woolcock Institute of Medical Research Vietnam, Ho Chi Minh City, Vietnam; ${ }^{4}$ Department of Medicine and Pharmacy, Tra Vinh University, Tra Vinh, Vietnam
Correspondence: Truc Thanh Thai Faculty of Public Health, University of Medicine and Pharmacy at Ho Chi Minh City, Ho Chi Minh City, Vietnam Tel +84 90838I 266

Email thaithanhtruc@ump.edu.vn

Tap Van Nguyen

Department of Medicine and Pharmacy,

Tra Vinh University, Tra Vinh, Vietnam

Tel +84914064340

Email nvtap@tvu.edu.vn
Purpose: Research conducted across different countries has consistently identified nonsuicidal self-injury (NSSI) to be a common and significant public health problem. This study examined the prevalence, associated factors and functions of NSSI, among a large sample of Vietnamese adolescents.

Methods: A total of 1316 high school students (15-18 years old, 63.3\% female) across urban and suburban areas in Ho Chi Minh City, participated in this cross-sectional study. NSSI was assessed by the Functional Assessment of Self-Mutilation.

Results: Almost half (43.9\%) of the adolescents engaged in at least one type of NSSI within the preceding 12-month period and more than one quarter $(26.1 \%)$ engaged in multiple types of NSSI. Hitting self on purpose (23.1\%), picking at a wound $(17.0 \%)$, or biting self $(16.7 \%)$ were the most frequent behaviours. Severe forms of NSSI such as scraping, burning or erasing skin were reported by $17.2 \%$. The most common functions for NSSI were to stop bad feelings $(56.0 \%)$, to punish self $(48.7 \%)$, to get control of a situation $(44.0 \%)$ and to feel relaxed (42.2\%). Symptoms of depression, anxiety and stress were significant factors associated with NSSI, particularly for participants who engaged in moderate/severe NSSI and multiple types of NSSI.

Conclusion: High rates of NSSI were found in Vietnamese adolescents. There is a pressing need for the development and implementation of effective interventions to reduce NSSI. Strategies that promote positive mental health and reduce symptoms of depression, anxiety and stress as well as approaches that help adolescents manage their internal emotions are likely to be beneficial.

Keywords: non-suicidal self-injury, functions, high school students, adolescents, associated factors, Vietnam

\section{Introduction}

Nonsuicidal self-injury (NSSI) refers to the deliberate self-inflicted destruction or modification of body tissue without the intent to die. ${ }^{1}$ Cutting, scratching, burning and biting one's skin are examples of NSSI behaviours, ${ }^{2}$ whereas modifying one's body tissue for culturally sanctioned reasons are not. ${ }^{3}$ While approximately four percent of adults in non-clinical samples report having engaged in self-injury at some point in their lifetime, ${ }^{4}$ adolescents report significantly higher rates. ${ }^{5}$ A systematic review of studies conducted in adolescent community samples between 2005 and 2011 reported an overall pooled international NSSI prevalence of $17.2 \%{ }^{6}$ Research conducted by Giletta, Scholte, Engels, Ciairano and Prinstein ${ }^{7}$ found that $24 \%$ of 1862 adolescents had engaged in at least one NSSI during the previous year. NSSI has been associated with a variety of clinical and functional 
impairments including substance use and symptoms of depression, ${ }^{7}$ infected wounds and scarring and is a strong predictor of future suicide. ${ }^{8,9}$ Additionally, NSSI may persist into adulthood ${ }^{10}$ and the majority of adolescents who experience NSSI never seek medical treatment. ${ }^{11}$ Given the high prevalence of NSSI and its associated negative consequences, NSSI is considered a significant clinical and public health issue and is included in the current edition of the Diagnostic and Statistical Manual of Mental Disorders, as a condition for further study. ${ }^{12}$

Research that helps elucidate the key factors that play a role in the development and maintenance of NSSI is crucial for the early detection, prevention and management of NSSI. A recent systematic review found gender to be the most important sociodemographic factor with female gender identified as a significant predictor of NSSI. ${ }^{13}$ The review also demonstrated that peer victimization, bullying and sexual abuse were significant environmental factors associated with NSSI and of the psychological variables investigated depressive symptomatology was the strongest NSSI predictor. ${ }^{13}$ The important relationship between symptoms of depression and NSSI has been reported in many studies employing large adolescent samples. One cross-sectional study of 12,068 adolescents across 11 European countries found that adolescents with depression had a 2.78 times higher risk of engaging in NSSI compared to adolescents without depression. ${ }^{11}$ A sample of 360 North American adolescents who experienced depressive symptoms had 4.58 times higher the risk of engaging in NSSI than those without depressive symptoms. ${ }^{7}$ Symptoms of anxiety or stress have also been found to be associated with NSSI. ${ }^{14}$

It has been proposed that individuals are motivated to engage in NSSI as these behaviours serve a number of functions. For example, NSSI in adolescents may function as a way to reduce psychological pain, to express and alleviate distress, and to distance themselves from negative emotional states such as anger, sadness, numbness or shame. ${ }^{11,15}$ In China and other Asian countries where academic performance is often viewed as a key measure of the success of an adolescent, school problems, academic stress and self-punishment could be important reasons for NSSI. $^{16-18}$ Unfortunately, there is a relative lack of research examining NSSI in the Asian region. A systematic review of NSSI studies included only $7 \%$ that had been conducted in Asia, two in China, one in Hong Kong, compared to $49.2 \%$ conducted in the USA and $16.5 \%$ in Europe. ${ }^{6}$
To our knowledge, to date only two studies have been conducted in Vietnam. In the most recent study of 1043 secondary school students aged $12-15$ years in HCMC and Binh Duong province, $27 \%$ of participants were found to have experienced NSSI at some point in their life based on the 5-item scale designed for that study. ${ }^{19}$ Research conducted by Le, Nguyen, Tran and Fisher ${ }^{20}$ investigated the prevalence of a range of mental health problems and their correlates, including self-harm behaviours among adolescents in Vietnam using data from two national populationbased surveys: The Survey Assessment of Vietnamese Youth (SAVY) I (2003-2004) (The General Statistics Office of Vietnam 2006) and II (2009-2010) (The General Statistics Office of Vietnam 2011). A total of 4609 adolescents aged 14-19 years participated in SAVY I and 6508 in SAVY II. Participants included all adolescents irrespective of whether they were enrolled in school or not. Data for both surveys were gathered through structured interviews and self-report questionnaires.

Both surveys asked participants if they had ever tried to injure themselves (not including tattoo). Responses to this question identified a history of self-harming behaviours of $2.80 \%$ for SAVY I and $9.15 \%$ for SAVY II. Given the wording of this question it is not possible to establish conclusively whether the attempt/s at self-injury were suicidal in nature or not. However, given that participants were also asked in a separate question if they had ever tried to attempt suicide and very low rates were identified $(0.003 \%$ indicated yes in SAVY I and $0.010 \%$ in SAVY II), it seems reasonable to conclude that the $2.8 \%$ and $9.15 \%$ is indicative of self-harm behaviours without intent to cause death, ie, NSSI. High levels of low mood defined as any experiences of helplessness or hopelessness were identified, with $34.06 \%$ of adolescents in SAVY I reporting a lifetime experience of low mood and $37.34 \%$ in SAVY II.

Unfortunately, the absence of a standardized and commonly used scale to measure NSSI in these two studies might affect the estimate and comparability of the study findings. As such, research examining NSSI in Vietnam using an alternative methodology is warranted. Additionally, findings from previous studies in other countries may not be relevant to the Vietnamese context due to both systematic and individual differences. While mental health is not prioritized in Vietnam, Vietnamese adolescents have been shown to have a high burden of mental health disorders, health risk behaviours and suicide as well as a low level of mental health literacy. Cultural 
differences including the importance of family and community, academic achievement and religion, may contribute to the dissimilarity of findings in NSSI across different countries. Therefore, more studies investigating the prevalence, associated factors and functions of NSSI are needed in Vietnam. As such, the aim of the current study is to further investigate the prevalence of NSSI among Vietnamese adolescents and also explore the correlates and functions of NSSI in this cohort.

\section{Methods}

\section{Settings, Study Design and Participants}

Vietnam is a densely populated Southeast Asian country with a population of 97 million people, $65 \%$ of whom live in rural areas. ${ }^{21}$ Nearly $20 \%$ of the population are adolescents. Ho Chi Minh City (HCMC) is the economic centre of the country with a population of 10 million people across 24 districts (15 urban and 9 suburban).

A cross-sectional study was conducted during three consecutive weeks in May 2019 of high school students enrolled in grades 10, 11 and 12 in both urban and suburban areas in HCMC. A multi-stage sampling technique was employed to recruit participants. A total of six districts (three urban and three suburban) were first selected using a simple random sampling technique (lottery method) based on a pre-existing list of 24 districts in HCMC. Then using the same selection approach, one high school was randomly selected from the list of high schools at each of the six districts. Finally, two classes were randomly selected for each of the three grades at each of these six schools. This resulted in a total of 36 classes. In total, there were 1812 students across these 36 classes, and all were invited to participate in this study. Figure 1 presents the participant recruitment flowchart.

\section{Study Procedure}

All research procedures were approved by the ethics committee at University of Medicine and Pharmacy at HCMC. Participation was by informed consent and was completely voluntary and anonymous. An active consent approach was used for this study where either father or mother of the students provided written informed consent by filling in a form to approve the students' participation in the study. A total of 1812 questionnaire booklets which included a participation information sheet, a consent form and a questionnaire were provided to students on a single day during their class at school for them to take

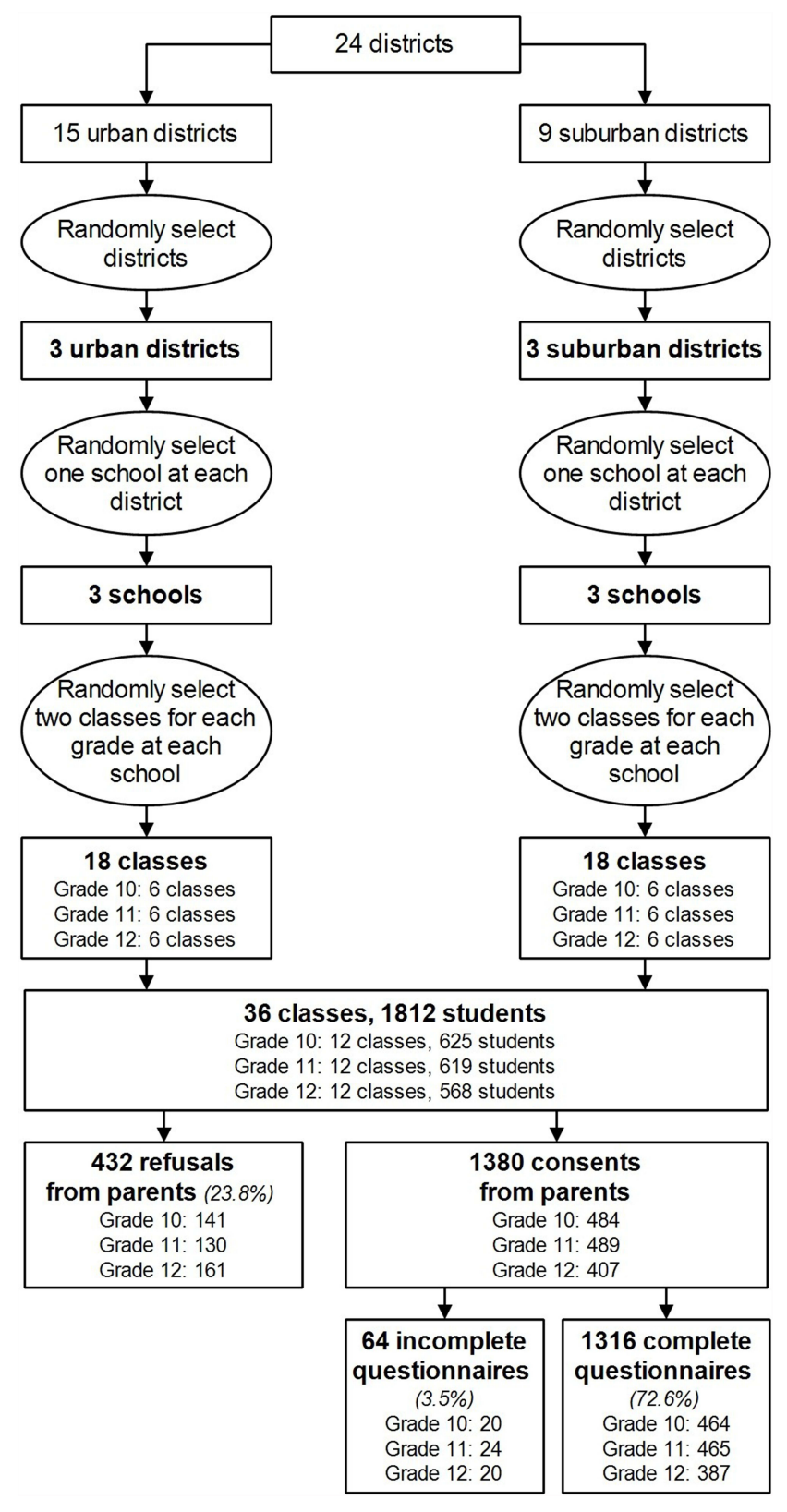

Figure I Recruitment flowchart.

home, complete overnight and return the next day. After receiving approval from parents and completing the selfreport questionnaire at home, students placed the questionnaire booklet in the provided envelope, sealed it at home and returned it to the researchers the next day. Parents of 432 students $(23.8 \%)$ did not provide consent for their child to participate in the study. An additional 64 students $(3.5 \%)$ received parental consent to participate but returned incomplete questionnaires. Therefore, a total of 1316 questionnaires were included in the analysis (see Figure 1). Information was provided to students on the participation information sheet regarding who to contact if 
their participation in the study caused them any distress and also who they could contact if they wanted to talk with a health professional about NSSI.

\section{Measures}

The self-report questionnaire investigated demographic characteristics (sex [male, female], religious affiliation [yes, no], parental marital status [married or living together, separated or divorced, father or mother died], parental education $[\leq$ high school, $>$ high school], family economic status [poor, normal, rich], and experience of physical or emotional violence in family [yes, no]). School and study related factors were also evaluated including whether the student had: joined any of their school's clubs [yes, no], often imposed pressure on themselves to study [yes, no], shared emotional states with friends [yes, no], experienced violence at school [yes, no], experienced educational pressure at school [yes, no]. Participants were also asked to indicate their grade point average last semester [excellent, average, lower], their relationship with teachers [good, normal, bad] and relationship with peers [good, normal, bad].

The Depression Anxiety Stress Scale (DASS-21) has 21 items that measures symptoms of depression (7 items, DASS-21-D), anxiety (7 items, DASS-21-A) and stress (7 items, DASS-21-S) that the person has experienced over the past week using a 4-point Likert-type rating scale from 0 (did not apply to me at all - NEVER) to 3 (applied to me very much, or most of the time - ALMOST ALWAYS). ${ }^{22}$ The total score is multiplied by 2 to get the overall score for each domain and the cut-off scores of 14, 10 and 19 are used to identify moderate and severe symptoms of depression, anxiety and stress, respectively. ${ }^{22}$ The scale has been translated into Vietnamese, and used in previous research in Vietnam where a high level of reliability and validity was reported. ${ }^{23}$ The Cronbach's alpha to measure the internal consistency is 0.88 for the overall scale and ranges from 0.70 to 0.77 for the subscales. The area under the curve (AUC) ranging from 79.2 to 83.1 indicates high level of predictive validity. ${ }^{23}$

The Functional Assessment of Self-Mutilation (FASM; Lloyd, Kelley and $\mathrm{Hope}^{2}$ ) was used to assess frequency and functions of NSSI in the past year. The first part consists of a checklist of 11 different NSSI behaviours including moderate/severe NSSI (cut or carve skin, scrape skin, burn skin, erase skin and give self a tattoo) and minor NSSI (hit self on purpose, bite self, pull hair out, insert objects under nails/skin, pick at a wound and pick areas of body to the point of drawing blood). For each of the NSSI listed the respondent is also asked to indicate the length of time they contemplated the behaviour(s) and whether or not they got medical treatment after performing the NSSI. However, in our pilot study, the majority of students failed to answer these two questions. Consequently, these two questions were removed from the survey. Participants were also asked whether they performed any of these behaviours as a suicide attempt.

The second part of the FASM examines the reasons and motivations for NSSI using a list of 22 pre-defined statements. Each statement is rated on a four-point Likert scale including never, rarely, sometimes and often. These statements are classified into four functions of NSSI: automatic-negative reinforcement, automatic-positive reinforcement, social negative reinforcement, and social-positive reinforcement. ${ }^{24}$ The internal reliability was moderate to excellent with Cronbach's alpha ranging from 0.62 to 0.85 and the construct validity was confirmed through confirmatory factor analysis. ${ }^{24}$ In this study, the FASM was translated into Vietnamese independently by two researchers. The differences in translated versions were discussed and the final version was agreed upon and tested in a pilot study among 30 students.

\section{Analysis}

All data analyses were conducted using Stata statistical software (version 15). Frequency and percentage were used to describe frequency and functions of NSSI. The difference between students with and without NSSI were evaluated using Chi-squared tests or Fisher's exact tests as appropriate. The level of association was measured through univariate logistic regression and was reported as odds ratio and its $95 \%$ confidence interval. Multivariate logistic regression models were used to identify independent associated factors of NSSI. Bayesian Model Averaging approach was used for variable selection due to its superiority compared to stepwise approach as suggested by Wang et al. ${ }^{25} \mathrm{~A}$ significance level of 0.05 was chosen for all two-tailed statistical tests used.

\section{Results}

\section{Participant Characteristics}

Among the 1316 Vietnamese high school students aged 1518 years old who participated in this study, 61 reported performing NSSI behaviours during a suicide attempt. Based on the definition of NSSI, these students' data were excluded from further analysis. Table 1 presents the characteristics of the remaining 1255 students. The majority were 
Table I Characteristics of Vietnamese High School Student Sample $(N=1255)$

\begin{tabular}{|c|c|c|c|}
\hline \multicolumn{2}{|l|}{ Characteristics } & $\mathbf{n}$ & $\%$ \\
\hline \multicolumn{4}{|l|}{ Demographics } \\
\hline \multirow[t]{2}{*}{ Sex } & Male & $47 \mid$ & 37.5 \\
\hline & Female & 784 & 62.5 \\
\hline \multirow[t]{3}{*}{ Grade } & 10 & 442 & 35.2 \\
\hline & II & 447 & 35.6 \\
\hline & 12 & 366 & 29.2 \\
\hline \multirow[t]{3}{*}{ Religious affiliation } & Yes & 563 & 44.9 \\
\hline & No & 649 & 51.7 \\
\hline & $\begin{array}{l}\text { Refused to } \\
\text { answer }\end{array}$ & 43 & 3.4 \\
\hline \multirow[t]{5}{*}{ Parents' marital status } & $\begin{array}{l}\text { Married/living } \\
\text { together }\end{array}$ & 1037 & 82.6 \\
\hline & Separated or & 116 & 9.2 \\
\hline & Divorced & & \\
\hline & $\begin{array}{l}\text { Father or } \\
\text { mother died }\end{array}$ & 51 & 4. 1 \\
\hline & $\begin{array}{l}\text { Refused to } \\
\text { answer }\end{array}$ & 51 & 4.1 \\
\hline \multirow[t]{3}{*}{ Father's education } & sHigh school & 682 & 54.3 \\
\hline & >High school & 353 & 28.1 \\
\hline & $\begin{array}{l}\text { Do not know/ } \\
\text { no answer }\end{array}$ & 220 & 17.5 \\
\hline \multirow[t]{3}{*}{ Mother's education } & sHigh school & 644 & 51.3 \\
\hline & >High school & 319 & 25.4 \\
\hline & $\begin{array}{l}\text { Do not know/ } \\
\text { no answer }\end{array}$ & 292 & 23.3 \\
\hline \multirow[t]{3}{*}{ Family's economic status } & Poor & 98 & 7.8 \\
\hline & Normal & 1083 & 86.3 \\
\hline & Rich & 74 & 5.9 \\
\hline \multirow{3}{*}{$\begin{array}{l}\text { Experience of physical or } \\
\text { emotional violence in family }\end{array}$} & Yes & 70 & 5.6 \\
\hline & No & 1096 & 87.3 \\
\hline & $\begin{array}{l}\text { Refused to } \\
\text { answer }\end{array}$ & 89 & 7.1 \\
\hline \multicolumn{4}{|l|}{ Study and school } \\
\hline \multirow[t]{3}{*}{ Grade point average } & Excellent & 677 & 53.9 \\
\hline & Normal & 440 & 35.1 \\
\hline & $\begin{array}{l}\text { Average or } \\
\text { lower }\end{array}$ & 138 & 11.0 \\
\hline \multirow[t]{2}{*}{ Joined school's club } & Yes & 340 & 27.1 \\
\hline & No & 915 & 72.9 \\
\hline \multirow{2}{*}{$\begin{array}{l}\text { Often impose pressure on yourself } \\
\text { to study }\end{array}$} & Yes & 945 & 75.3 \\
\hline & No & 310 & 24.7 \\
\hline \multirow[t]{2}{*}{ Share emotional states with friends } & Yes & 1035 & 82.5 \\
\hline & No & 220 & 17.5 \\
\hline
\end{tabular}

(Continued)
Table I (Continued).

\begin{tabular}{|c|c|c|c|}
\hline \multicolumn{2}{|l|}{ Characteristics } & \multirow{2}{*}{$\begin{array}{r}\mathbf{n} \\
224\end{array}$} & \multirow{2}{*}{$\begin{array}{l}\% \\
17.8\end{array}$} \\
\hline Relationship with teachers at & Good & & \\
\hline school & Normal & 994 & 79.2 \\
\hline & Bad & 37 & 2.9 \\
\hline \multirow[t]{3}{*}{ Relationship with peers } & Good & 635 & 50.6 \\
\hline & Normal & 584 & 46.5 \\
\hline & $\mathrm{Bad}$ & 36 & 2.9 \\
\hline \multirow[t]{3}{*}{ Experience school violence } & Yes & 128 & 10.2 \\
\hline & & 1056 & 84.1 \\
\hline & $\begin{array}{l}\text { Refused to } \\
\text { answer }\end{array}$ & 71 & 5.7 \\
\hline \multirow{2}{*}{$\begin{array}{l}\text { Experience educational pressure at } \\
\text { school }\end{array}$} & Yes & 846 & 67.4 \\
\hline & No & 409 & 32.6 \\
\hline \multicolumn{4}{|l|}{ Mental health symptoms } \\
\hline Stress & & 412 & 32.8 \\
\hline Anxiety & & 712 & 56.7 \\
\hline Depression & & 431 & 34.3 \\
\hline Number of mental health & 0 & 432 & 34.4 \\
\hline \multirow[t]{3}{*}{ symptoms } & I & 350 & 27.9 \\
\hline & 2 & 214 & 17.1 \\
\hline & 3 & 259 & 20.6 \\
\hline
\end{tabular}

female (62.5\%), had no religious affiliation (51.7\%), and had parents who were married and living together $(82.6 \%)$. More than half of the students reported their parents having an education level of high school or lower $(54.3 \%$ fathers and $51.3 \%$ mothers). Less than $10 \%$ reported poor economic status or family violence. In terms of study and school, more than half of the students reported that they had an excellent grade point average (53.9\%). The majority of students reported having imposed pressure on themselves to study $(75.3 \%)$ or had experienced educational pressure at school (67.4\%). Almost all students reported normal or good relationships with their teachers $(97.1 \%)$ and peers (97.1\%) at school. The percentage of students with cut-off scores of 14, 10 and 19 respectively indicating moderate to severe symptoms of depression, anxiety or stress was $32.8 \%$, $56.7 \%$ and $34.3 \%$. More than one-third (37.7\%) had symptoms of two (17.1\%) or more (20.6\%) of these mental health conditions.

\section{Prevalence of Nonsuicidal Self-Injury}

Table 2 presents the number and proportion of the participants who reported engaging in NSSI as well as the types of NSSI. Over $40 \%$ of students reported engaging in at least one NSSI in the past year. Overall, minor NSSI were more 
Table 2 NSSI in Vietnamese High School Students (1255)

\begin{tabular}{|c|c|c|c|c|}
\hline NSSI & Total n (\%) & Female n (\%) & Male $n(\%)$ & $\mathbf{p}$ \\
\hline \multicolumn{5}{|l|}{ Minor NSSI } \\
\hline Hit self on purpose & $290(23.1)$ & $18 \mid(23.1)$ & $109(23.1)$ & 0.982 \\
\hline Picked at a wound & $213(17.0)$ & $124(15.8)$ & $89(18.9)$ & 0.159 \\
\hline Bite self & $209(16.7)$ & $142(18.1)$ & $67(14.2)$ & 0.073 \\
\hline Pulled hair out & $184(14.7)$ & $100(12.8)$ & $84(17.8)$ & 0.014 \\
\hline Picked areas of body to the point of drawing blood & $47(3.7)$ & $29(3.7)$ & $18(3.8)$ & 0.912 \\
\hline Inserted objects under nails or skin & $39(3.1)$ & $22(2.8)$ & $17(3.6)$ & 0.427 \\
\hline \multicolumn{5}{|l|}{ Moderate/severe NSSI } \\
\hline Cut or carved skin & $65(5.2)$ & $43(5.5)$ & $22(4.7)$ & 0.529 \\
\hline Scraped skin & $54(4.3)$ & $30(3.8)$ & $24(5.1)$ & 0.283 \\
\hline Burned skin & $54(4.3)$ & $24(3.1)$ & $30(6.4)$ & 0.005 \\
\hline Gave self a tattoo & $45(3.6)$ & $30(3.8)$ & $15(3.2)$ & 0.554 \\
\hline Erased skin & $18(1.4)$ & $13(1.7)$ & $5(1.1)$ & 0.389 \\
\hline \multicolumn{5}{|l|}{ Multiple NSSI } \\
\hline \multicolumn{5}{|l|}{ Number of minor NSSI } \\
\hline 0 & $738(58.8)$ & $46 I(58.8)$ & $277(58.8)$ & 0.330 \\
\hline I & $240(19.1)$ & $156(19.9)$ & $84(17.8)$ & \\
\hline 2 & $156(12.4)$ & $100(12.8)$ & $56(11.9)$ & \\
\hline$\geq 3$ & $|2|(9.6)$ & $67(8.5)$ & $54(11.5)$ & \\
\hline \multicolumn{5}{|l|}{ Number of moderate/severe NSSI } \\
\hline 0 & $1072(85.4)$ & $676(86.2)$ & $396(84.1)$ & 0.579 \\
\hline I & $143(\mid \mathrm{l} .4)$ & $83(10.6)$ & $60(12.7)$ & \\
\hline 2 & $27(2.2)$ & $18(2.3)$ & $9(1.9)$ & \\
\hline$\geq 3$ & $13(1.0)$ & $7(0.9)$ & $6(1.3)$ & \\
\hline \multicolumn{5}{|l|}{ Number of all NSSI } \\
\hline 0 & $704(56.1)$ & $444(56.6)$ & $260(55.2)$ & 0.693 \\
\hline I & $223(17.8)$ & $143(18.2)$ & $80(17.0)$ & \\
\hline 2 & $157(12.5)$ & 92 (II.7) & $65(13.8)$ & \\
\hline$\geq 3$ & $|7|(\mid 3.6)$ & $105(13.4)$ & $66(14.0)$ & \\
\hline
\end{tabular}

Notes: NSSI items adapted with permission from: Lloyd-Richardson EE, Perrine N, Dierker L, Kelley ML. Characteristics and functions of non-suicidal self-injury in a community sample of adolescents. Psychol Med. 2007;37(8): I 183-1192. doi:10.1017/S003329170700027X. ${ }^{28}$ Copyright @ Cambridge University Press 2007.

prevalent than moderate/severe NSSI (41.2\% and 14.6\%). Almost one quarter of students (23.1\%) hit themselves on purpose, $17.0 \%$ reported having picked at a wound and $16.7 \%$ reporting having bitten themselves. Approximately $5 \%$ cut or carved their skin. More than a quarter of students engaged in multiple types of NSSI (26.1\%). The prevalence of multiple minor NSSI and moderate/severe NSSI was $22.0 \%$ and $3.2 \%$, respectively. Males were significantly more likely than females to pull their hair out $(\mathrm{p}=0.014)$ or burn their skin $(p=0.005)$. No other significant differences for NSSI were found between males and females.

\section{Functions of Nonsuicidal Self-Injury}

Forty-two students did not disclose the reasons for engaging in NSSI behaviours. When the percentages reported for rarely, sometimes and often were combined for each of the 22 pre- defined statements, the most common reasons were to stop bad feelings $(56.0 \%)$, to punish themselves $(48.7 \%)$, to get control of a situation ( $44.0 \%)$ and to feel relaxed (42.2\%). For all of the 22 reasons, the percentages obtained for participants classified as engaging in moderate/severe NSSI were higher than those for participants classified as engaging in mild NSSI. These differences were significant for all reasons except for: to punish self, to avoid doing something unpleasant, to get control of a situation, to get parents to understand or notice, to receive more attention from parents or friends, to get help and to be like someone they respect. These results are presented in Table 3.

\section{Correlates of Nonsuicidal Self-Injury}

In the univariate analysis, higher odds of having engaged in NSSI was found among participants whose parents were separated or divorced $(\mathrm{OR}=1.68,95 \%$ CI 1.14 
Table 3 Reasons for NSSI According to Four Functions $(n=509)$

\begin{tabular}{|c|c|c|c|c|c|c|c|c|}
\hline \multirow[t]{2}{*}{ Reasons, $\mathbf{n}(\%)$} & \multicolumn{4}{|c|}{ Reasons } & \multirow[t]{2}{*}{ Total $^{\mathbf{a}}$} & \multicolumn{3}{|c|}{ NSSI } \\
\hline & Never & Rarely & Sometimes & Often & & Mild & $\begin{array}{l}\text { Moderatel } \\
\text { Severe }\end{array}$ & $\mathbf{p}$ \\
\hline \multicolumn{9}{|l|}{ Automatic negative reinforcement } \\
\hline To stop bad feelings & $224(44.0)$ & $148(29.1)$ & $92(18.1)$ & $45(8.8)$ & $285(56.0)$ & $166(5 \mid .2)$ & $119(64.3)$ & 0.003 \\
\hline To relieve feeling numb or empty & $333(65.4)$ & $94(18.5)$ & $59(11.6)$ & $23(4.5)$ & $176(34.6)$ & $92(28.4)$ & $84(45.4)$ & 0.001 \\
\hline \multicolumn{9}{|l|}{ Automatic positive reinforcement } \\
\hline To punish self & $261(51.3)$ & $118(23.2)$ & $76(14.9)$ & $54(10.6)$ & $248(48.7)$ & $156(48.1)$ & $92(49.7)$ & 0.619 \\
\hline To feel relaxed & $294(57.8)$ & $95(18.7)$ & $67(13.2)$ & $53(10.4)$ & $215(42.2)$ & $119(36.7)$ & $96(51.9)$ & 0.002 \\
\hline To feel something, even if it was pain & $304(59.7)$ & $112(22.0)$ & $73(14.3)$ & $20(3.9)$ & $205(40.3)$ & $117(36.1)$ & $88(47.6)$ & 0.014 \\
\hline \multicolumn{9}{|l|}{ Social negative reinforcement } \\
\hline To avoid doing something unpleasant & $309(60.7)$ & $124(24.4)$ & $63(12.4)$ & $13(2.6)$ & $200(39.3)$ & $123(38.0)$ & $77(4 \mid .6)$ & $0.94 I$ \\
\hline $\begin{array}{l}\text { To avoid school, work or other } \\
\text { activities }\end{array}$ & $379(74.5)$ & $95(18.7)$ & $29(5.7)$ & $6(1.2)$ & $130(25.5)$ & $71(21.9)$ & $59(31.9)$ & 0.025 \\
\hline To avoid being with people & $410(80.6)$ & $58(11.4)$ & $30(5.9)$ & II (2.2) & $99(19.4)$ & $4 \mid(\mid 2.7)$ & $58(31.4)$ & $<0.001$ \\
\hline $\begin{array}{l}\text { To avoid punishment or paying the } \\
\text { consequences }\end{array}$ & $435(85.5)$ & $50(9.8)$ & $17(3.3)$ & $7(1.4)$ & $74(14.5)$ & $32(9.9)$ & $42(22.7)$ & $<0.001$ \\
\hline \multicolumn{9}{|l|}{ Social positive reinforcement } \\
\hline To get control of a situation & $285(56.0)$ & $124(24.4)$ & $66(13.0)$ & $34(6.7)$ & $224(44.0)$ & $134(4 \mid .4)$ & $90(48.6)$ & 0.391 \\
\hline $\begin{array}{l}\text { To give yourself something to do } \\
\text { when alone }\end{array}$ & $366(71.9)$ & $82(16.1)$ & $33(6.5)$ & $28(5.5)$ & $143(28.1)$ & $79(24.4)$ & $64(34.6)$ & 0.011 \\
\hline $\begin{array}{l}\text { To get your parents to understand } \\
\text { or notice you }\end{array}$ & $375(73.7)$ & $76(14.9)$ & $37(7.3)$ & $21(4.1)$ & $134(26.3)$ & $77(23.8)$ & $57(30.8)$ & 0.053 \\
\hline $\begin{array}{l}\text { To receive more attention from } \\
\text { your parents or friends }\end{array}$ & $379(74.5)$ & $88(17.3)$ & $31(6.1)$ & II (2.2) & $130(25.5)$ & $76(23.5)$ & $54(29.2)$ & 0.169 \\
\hline $\begin{array}{l}\text { To try to get a reaction from } \\
\text { someone, even if it's a negative } \\
\text { reaction }\end{array}$ & $383(75.2)$ & $83(16.3)$ & $37(7.3)$ & $6(1.2)$ & $126(24.8)$ & $60(18.5)$ & $66(35.7)$ & $<0.001$ \\
\hline $\begin{array}{l}\text { To let others know how desperate } \\
\text { you were }\end{array}$ & $380(74.7)$ & $76(14.9)$ & $35(6.9)$ & $18(3.5)$ & $129(25.3)$ & $63(19.4)$ & $66(35.7)$ & $<0.001$ \\
\hline $\begin{array}{l}\text { To get other people to act } \\
\text { differently or change }\end{array}$ & $40 I(78.8)$ & $70(13.8)$ & $26(5.1)$ & $12(2.4)$ & $108(21.2)$ & $53(16.4)$ & 55 (29.7) & $<0.001$ \\
\hline To get help & $410(80.6)$ & $60(11.8)$ & $29(5.7)$ & $10(2)$ & $99(19.4)$ & $56(17.3)$ & $43(23.2)$ & 0.042 \\
\hline To get attention & $434(85.3)$ & $51(10)$ & $17(3.3)$ & $7(1.4)$ & $75(14.7)$ & $39(12.0)$ & $36(19.5)$ & 0.012 \\
\hline To feel more a part of a group & $429(84.3)$ & $48(9.4)$ & $24(4.7)$ & $8(1.6)$ & $80(15.7)$ & $37(11.4)$ & $43(23.2)$ & $<0.001$ \\
\hline To make others angry & $438(86.1)$ & $50(9.8)$ & $13(2.6)$ & $8(1.6)$ & $71(13.9)$ & $33(10.2)$ & $38(20.5)$ & 0.008 \\
\hline $\begin{array}{l}\text { To give yourself something to do } \\
\text { when with others }\end{array}$ & $448(88.0)$ & $37(7.3)$ & $20(3.9)$ & $4(0.8)$ & $61(12.0)$ & $27(8.3)$ & $34(18.4)$ & 0.001 \\
\hline To be like someone you respect & $486(95.5)$ & $17(3.3)$ & $4(0.8)$ & $2(0.4)$ & $23(4.5)$ & II (3.4) & $12(6.5)$ & 0.116 \\
\hline
\end{tabular}

Notes: ${ }^{\mathrm{a}}$ Rarely, sometimes and often. NSSI reasons adapted with permission from: Lloyd-Richardson EE, Perrine N, Dierker L, Kelley ML. Characteristics and functions of non-suicidal self-injury in a community sample of adolescents. Psychol Med. 2007;37(8): I 183-1192. doi:10.1017/S003329170700027X. ${ }^{28}$ Copyright $\odot$ Cambridge University Press 2007.

2.47) and those who experienced family violence $(\mathrm{OR}=2.39,95 \%$ CI 1.45-3.94). Additionally, participants who often imposed pressure on themselves to study $(\mathrm{OR}=1.38,95 \%$ CI 1.06-1.79), did not share emotional states with friends $(\mathrm{OR}=1.37,95 \% \mathrm{CI}$ 1.03-1.85), experienced school violence $(\mathrm{OR}=1.70$, $95 \%$ CI 1.17-2.46) and had educational pressure at school $(\mathrm{OR}=1.40,95 \%$ CI $1.10-1.78)$ were more likely to have engaged in NSSI. Higher odds of having engaged in NSSI was also found among participants with symptoms of depression $(\mathrm{OR}=2.01,95 \% \mathrm{CI}$ 1.59-2.55), anxiety ( $\mathrm{OR}=1.86,95 \% \mathrm{CI} 1.48-2.34)$ or stress $(\mathrm{OR}=2.46,95 \%$ CI 1.93-3.13) compared to those without symptoms of depression, anxiety and stress. 
Table 4 Univariate Association Between Participants' Characteristics and Self-Injury Behaviours

\begin{tabular}{|c|c|c|c|c|c|}
\hline \multirow[t]{3}{*}{ Characteristics } & & \multicolumn{2}{|c|}{ NSSI n (\%) } & \multirow[t]{3}{*}{$\mathbf{p}$} & \multirow[t]{3}{*}{ OR $(95 \% \mathrm{Cl})$} \\
\hline & & Yes & No & & \\
\hline & & $\begin{array}{l}n=551 ; \\
43.9 \%\end{array}$ & $\begin{array}{c}n=704 \\
56.1 \%\end{array}$ & & \\
\hline \multicolumn{6}{|l|}{ Demographics } \\
\hline \multirow[t]{2}{*}{ Sex } & Male & $211(38.3)$ & $260(36.9)$ & 0.621 & $1.06(0.84-1.33)$ \\
\hline & Female & $340(6 \mid .7)$ & $444(63.1)$ & & I \\
\hline \multirow[t]{3}{*}{ Grade } & 10 & $202(36.7)$ & $240(34.1)$ & 0.145 & 1 \\
\hline & 11 & $204(37.0)$ & $243(34.5)$ & & $1.00(0.77-1.30)$ \\
\hline & 12 & $145(26.3)$ & $221(31.4)$ & & $0.78(0.59-1.03)$ \\
\hline \multirow{3}{*}{ Religious affiliation } & Yes & $237(43.0)$ & $326(46.3)$ & 0.372 & $0.89(0.7 I-I . \mid 2)$ \\
\hline & No & $292(53.0)$ & $357(50.7)$ & & 1 \\
\hline & Refused to answer & $22(4.0)$ & $21(3.0)$ & & $1.28(0.69-2.38)$ \\
\hline \multirow[t]{4}{*}{ Parents' marital status } & Married/living together & $439(79.7)$ & $598(84.9)$ & 0.019 & I \\
\hline & Separated or Divorced & $64(11.6)$ & $52(7.4)$ & & $1.68(1.14-2.47)$ \\
\hline & Father or mother died & $28(5.1)$ & $23(3.3)$ & & $1.66(0.94-2.92)$ \\
\hline & Refused to answer & $20(3.6)$ & $31(4.4)$ & & $0.88(0.49-1.56)$ \\
\hline \multirow{3}{*}{ Father's education } & $\leq$ High school & $295(53.5)$ & $387(55.0)$ & 0.008 & 1 \\
\hline & $>$ High school & $140(25.4)$ & $213(30.3)$ & & $0.86(0.66-1.12)$ \\
\hline & $\begin{array}{l}\text { Do not know/not } \\
\text { answer }\end{array}$ & $116(21.1)$ & $104(14.8)$ & & $1.46(1.08-1.98)$ \\
\hline \multirow[t]{3}{*}{ Mother's education } & $\leq$ High school & $277(50.3)$ & $367(52.1)$ & 0.083 & 1 \\
\hline & >High school & $130(23.6)$ & $189(26.8)$ & & $0.91(0.69-1.20)$ \\
\hline & $\begin{array}{l}\text { Do not know/not } \\
\text { answer }\end{array}$ & I44 (26.I) & $148(2 \mid .0)$ & & $1.29(0.98-1.70)$ \\
\hline \multirow[t]{3}{*}{ Family's economic status } & Poor & $43(7.8)$ & $55(7.8)$ & 0.937 & $0.99(0.65-1.51)$ \\
\hline & Normal & $477(86.6)$ & $606(86.1)$ & & 1 \\
\hline & Rich & $31(5.6)$ & $43(6.1)$ & & $0.92(0.57-1.48)$ \\
\hline \multirow{3}{*}{$\begin{array}{l}\text { Experience of physical or emotional violence in } \\
\text { family }\end{array}$} & Yes & $44(8.0)$ & $26(3.7)$ & $<0.001$ & $2.39(1.45-3.94)$ \\
\hline & No & $454(82.4)$ & $642(91.2)$ & & 1 \\
\hline & Refused to answer & $53(9.6)$ & $36(5.1)$ & & $2.08(1.34-3.23)$ \\
\hline \multicolumn{6}{|l|}{ Study and school } \\
\hline \multirow[t]{3}{*}{ Grade point average } & Excellent & $291(52.8)$ & $386(54.8)$ & 0.231 & $0.99(0.78-1.26)$ \\
\hline & Normal & $190(34.5)$ & $250(35.5)$ & & 1 \\
\hline & Average or lower & $70(12.7)$ & $68(9.7)$ & & $1.35(0.92-1.99)$ \\
\hline \multirow[t]{2}{*}{ Joined school's club } & Yes & $160(29.0)$ & $180(25.6)$ & 0.170 & $1.19(0.93-1.53)$ \\
\hline & No & $391(71.0)$ & $524(74.4)$ & & 1 \\
\hline \multirow[t]{2}{*}{ Often impose pressure on yourself to study } & Yes & $433(78.6)$ & $512(72.7)$ & 0.017 & $1.38(1.06-1.79)$ \\
\hline & No & II 8 (2I.4) & $192(27.3)$ & & 1 \\
\hline \multirow[t]{2}{*}{ Share emotional states with friends } & Yes & $440(79.9)$ & $595(84.5)$ & 0.031 & 1 \\
\hline & No & III (20.I) & $109(15.5)$ & & $1.37(1.03-1.85)$ \\
\hline \multirow[t]{3}{*}{ Relationship with teachers at school } & Good & $98(17.8)$ & $126(17.9)$ & 0.278 & $1.01(0.76-1.36)$ \\
\hline & Normal & $432(78.4)$ & $562(79.8)$ & & 1 \\
\hline & Bad & $21(3.8)$ & $16(2.3)$ & & $1.71(0.88-3.31)$ \\
\hline
\end{tabular}

(Continued) 
Table 4 (Continued).

\begin{tabular}{|c|c|c|c|c|c|}
\hline \multicolumn{2}{|l|}{ Characteristics } & \multicolumn{2}{|c|}{ NSSI n (\%) } & \multirow[t]{3}{*}{$\mathbf{p}$} & \multirow[t]{3}{*}{ OR $(95 \% \mathrm{Cl})$} \\
\hline & & Yes & No & & \\
\hline & & $\begin{array}{c}n=551 ; \\
43.9 \%\end{array}$ & $\begin{array}{c}n=704 \\
56.1 \%\end{array}$ & & \\
\hline Relationship with peers & $\begin{array}{l}\text { Good } \\
\text { Normal } \\
\text { Bad }\end{array}$ & $\begin{array}{c}269(48.8) \\
265(48.1) \\
17(3.1)\end{array}$ & $\begin{array}{c}366(52.0) \\
319(45.3) \\
19(2.7)\end{array}$ & 0.525 & $\begin{array}{c}0.88(0.7 I-I . I I) \\
I \\
I .08(0.55-2 . I I)\end{array}$ \\
\hline Experience of school violence & $\begin{array}{l}\text { Yes } \\
\text { No }\end{array}$ & $\begin{array}{c}70(12.7) \\
438(79.5)\end{array}$ & $\begin{array}{c}58(8.2) \\
618(87.8)\end{array}$ & $<0.001$ & $\begin{array}{c}1.70(1.18-2.46) \\
1\end{array}$ \\
\hline Experience educational pressure at school & $\begin{array}{l}\text { Refused to answer } \\
\text { Yes } \\
\text { No }\end{array}$ & $\begin{array}{c}43(7.8) \\
394(71.5) \\
157(28.5)\end{array}$ & $\begin{array}{c}28(4.0) \\
452(64.2) \\
252(35.8)\end{array}$ & 0.006 & $\begin{array}{c}2.17(1.33-3.54) \\
1.40(1.10-1.78) \\
I\end{array}$ \\
\hline Mental health symptoms & & & & & \\
\hline Stress & Yes & $242(43.9)$ & $170(24.1)$ & $<0.001$ & $2.46(1.93-3.13)$ \\
\hline Anxiety & Yes & $359(65.2)$ & $353(50.1)$ & $<0.001$ & $1.86(1.48-2.34)$ \\
\hline Depression & Yes & $238(43.2)$ & $193(27.4)$ & $<0.001$ & $2.01(1.59-2.55)$ \\
\hline Number of mental health symptoms & $\begin{array}{l}0 \\
1 \\
2 \\
3\end{array}$ & $\begin{array}{l}140(25.4) \\
144(26.1) \\
106(19.2) \\
16 \mid(29.2)\end{array}$ & $\begin{array}{c}292(41.5) \\
206(29.3) \\
108(15.3) \\
98(13.9)\end{array}$ & $<0.001$ & $\begin{array}{c}\mathrm{I} \\
\mathrm{I} .46(1.09-1.95) \\
2.05(1.46-2.86) \\
3.43(2.48-4.73)\end{array}$ \\
\hline
\end{tabular}

Further, experiencing more than one of these (ie, depression, anxiety or stress) was significantly associated with NSSI. These results can be seen in Table 4 .

Statistically significant factors reported in Table 4 (ie, parents' marital status, father's education, experience of physical or emotional violence in family, share emotional states with friends, experience of school violence, experience educational pressure at school and mental health symptoms) were used in multivariable analysis. Only symptoms of depression, anxiety or stress were found to be significant in the final models, with posterior probability ranging from $13.2 \%$ to $24.0 \%$. Figure 2 presents the association between symptoms of depression, anxiety and stress and NSSI with adjustment for the significant correlates presented in Table 4 . Students with depression, anxiety or stress symptoms had higher odds of having engaged in NSSI and multiple NSSI. Moreover, an increase in the number of these mental health symptoms was associated with an increased odds of having engaged in NSSI and multiple NSSI.

\section{Discussion}

This study is one of the very few to have explored NSSI in Vietnam. We found a very high prevalence of high school students having engaged in NSSI. Almost half (43.9\%) of the adolescents engaged in at least one type of NSSI within the preceding 12-month period with more than one quarter $(26.1 \%)$ reporting multiple methods of NSSI during that period. Our finding is higher than that reported in a study among secondary school students in Vietnam that identified $27 \%{ }^{19}$ Our findings are also markedly higher than those reported by Le et $\mathrm{al}^{20}$ who found a history of self-harming behaviours of $2.80 \%$ of Vietnamese adolescents from the Survey Assessment of Vietnamese Youth (SAVY) I (2003-2004) (The General Statistics Office of Vietnam 2006) and 9.15\%. of Vietnamese adolescents from The Survey Assessment of Vietnamese Youth SAVY II (2009-2010) (The General Statistics Office of Vietnam 2011).

The NSSI prevalence in our study is also higher than that reported from previous studies in high school students in China of $15 \%$ prevalence reported by You et $\mathrm{al}^{26}$ for the previous two-year period, and $11 \%$ reported by Wong et $\mathrm{al}^{27}$ in a sample of Chinese adolescents in Hong Kong. However, our finding is almost identical to that reported by Lloyd-Richardson et $\mathrm{al}^{28}$ who employed the same questionnaire, the FASM, in a sample of secondary school 


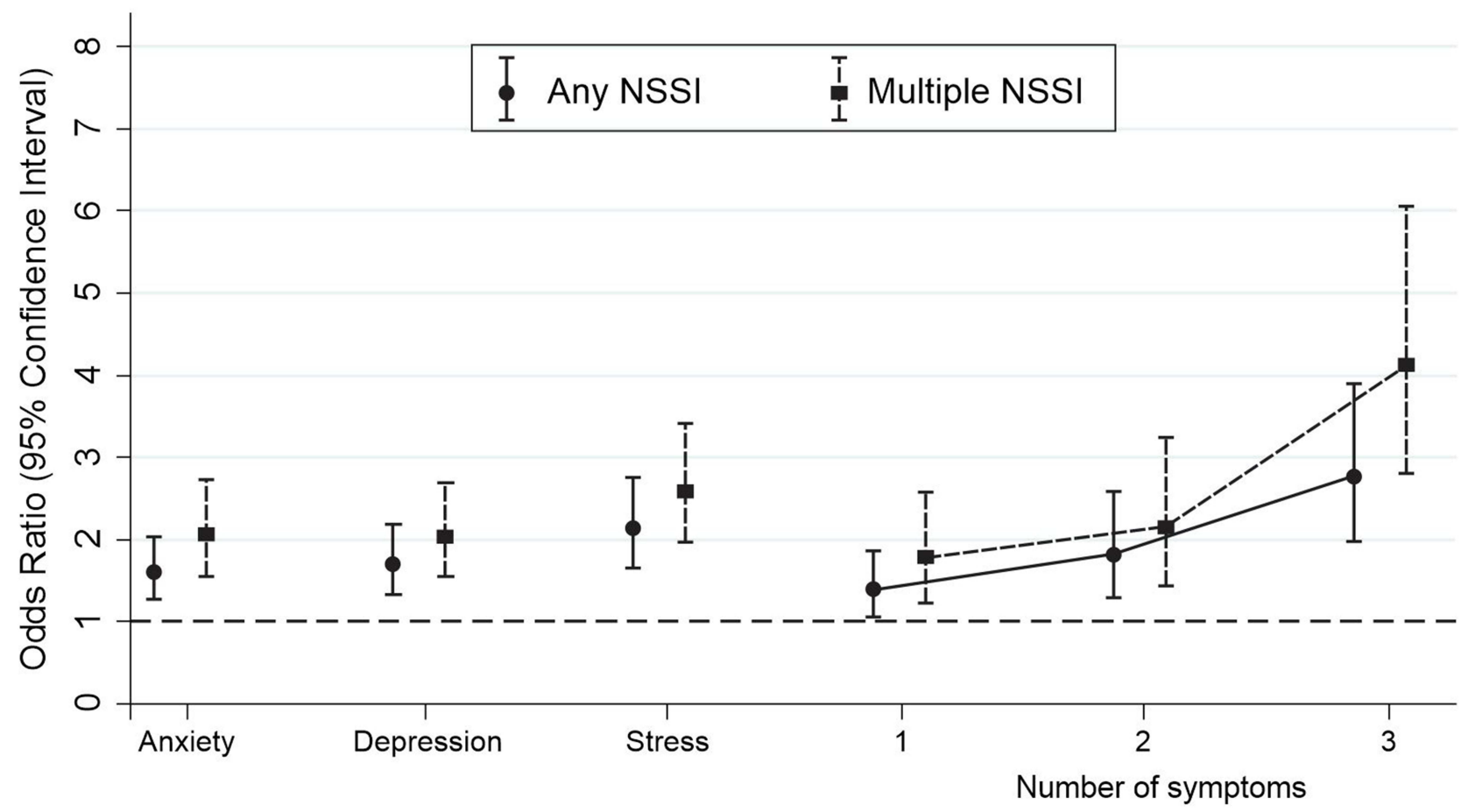

Mental health symptoms

Figure 2 The association between NSSI and mental health symptoms.

students in the USA in which $46.5 \%$ of participants had exhibited some form of NSSI within the preceding year.

These discrepancies might be due to differences in the definition of NSSI employed and the use of different NSSI assessment tools. Swannell et $\mathrm{al}^{6}$ reported that methodological factors contributed over half $(51.6 \%)$ of the heterogeneity in NSSI prevalence estimates in their systematic review and that checklists of NSSI methods lead to higher estimates than single-item questions. For example, while some studies such as the current study and that conducted by Lloyd-Richardson et $\mathrm{al}^{29}$ identified a high prevalence when using the FASM checklist measure, the prevalence of NSSI reported in other studies is lower possibly due the methodology used, that is, asking one question with a yes or no response. The high prevalence of NSSI in the current study suggests that NSSI is a significant issue that warrants early detection and referral to appropriate treatment programs.

In regard to which NSSI behaviours were most frequently engaged in, almost one quarter of students (23.1\%) in our sample hit themselves on purpose, $17 \%$ reported having picked at a wound and $16.7 \%$ reporting having bitten themselves. These findings are somewhat consistent with those of Lloyd-Richardson et $\mathrm{al}^{28}$ who found biting self, cutting/carving skin, hitting self on purpose, and burning skin to be the most frequent NSSI. In the current study, the five most common reasons for NSSI were to stop bad feelings $(56.0 \%)$, to punish themselves $(48.7 \%)$, to get control of a situation (44.0\%), to feel relaxed $(42.2 \%)$ and to feel something even if it was pain (40.3\%). The most common reasons for NSSI identified by Lloyd-Richardson et $\mathrm{al}^{28}$ were to try to get a reaction from someone, to get control of a situation, and to stop bad feelings. Therefore, trying to stop bad feelings and trying to get control of a situation were common reasons found in both the current study and the study conducted by LloydRichardson et al. ${ }^{28}$ As such, attempting to manage internal emotions appears to be an important contributory factor underpinning NSSI. Strategies that promote positive mental health and reduce symptoms of depression, anxiety and stress as well as approaches that assist adolescents manage their internal emotions are also likely to be beneficial. Helping adolescents develop positive coping skills and utilise methods to manage their stress such as mindfulnessbased therapy may be useful. Further, while there is a paucity of well-controlled studies examining treatment approaches to reduce NSSI a systematic review conducted by Turner et $\mathrm{al}^{30}$ identified that both psychological and 
pharmacological interventions showed some promise These included emotion regulation group therapy, dialectical behaviour therapy, manual-assisted cognitive therapy, dynamic deconstructive psychotherapy and atypical antipsychotics, naltrexone, and selective serotonin reuptake inhibitors.

Our findings demonstrated a particularly important relationship between the experience of symptoms of depression, anxiety, or stress and NSSI. Moreover, an increase in the number of these mental health symptoms was associated with an increased odds of having engaged in multiple methods of NSSI. The relationship between NSSI, depression, anxiety and stress has been previously reported. ${ }^{7,11}$ Adolescents who had symptoms of depression had 4.58 to 7.31 higher odds of having NSSI. ${ }^{7}$ In Vietnam, the prevalence of symptoms of mental disorders is high in adolescents. ${ }^{31,32}$ This might explain the high prevalence of NSSI found in this study and indicate a need for intervention for both mental health symptoms and NSSI. Students with multiple mental health symptoms had a much greater likelihood of having engaged in NSSI and multiple methods of NSSI. Therefore, further intervention programs should focus on this most vulnerable population.

While our findings contribute to the understanding of NSSI among adolescents in a low-income country, there are some limitations in this study. Although we had a large number of participants from both urban and suburban areas, our results are from one city only, a city that is the social and economic centre of Vietnam. This may limit the generalizability of our findings. More research with other adolescent samples in other areas of Vietnam including adolescents living in rural areas is warranted. Additionally, as all participants were school students, comparing rates of NSSI in adolescents who do and do not attend school could shed further light on this important issue. As such, more research in Vietnam with a more diverse sample of adolescents is required. Moreover, the high rate of parents who did not provide consent for their child to participate in this study could lead to potential biases. We did not have data that would allow us to compare students who participated in the study with students who did not and thus we are unable to understand if there are differences between the two groups. From discussions with some of the students, it appears that a number of factors may have impacted on the rate of parental consent. These included parents not having sufficient time to read and sign the consent form, parental fear of their children disclosing sensitive family issues when answering the questions and students living with relatives who were not legal guardians and thus could not provide consent. We suggest it would be helpful to address these issues in future research of this kind.

Due to the nature of cross-sectional research, we are unable to conclude the casual relationship between symptoms of depression, anxiety or stress and NSSI. It is not known whether experiencing these mental health symptoms leads to NSSI, or whether NSSI causes these mental health symptoms. Moreover, in this study, the sample size limited us from stratification analysis (ie, no NSSI, minor NSSI only, moderate/severe NSSI only and both minor NSSI and moderate/severe NSSI) to understand whether mental health symptoms lead to minor or moderate/severe NSSI. Longitudinal research with larger sample sizes may be able to help tease out the nature of the direction of this relationship. We also suggest that mixed method research may be beneficial in elucidating the underlying reasons why adolescents engage in NSSI. For example, Ong et $\mathrm{al}^{33}$ conducted in-depth interviews with Singaporean adolescents to explore the reasons for NSSI.

We acknowledge that as adolescents were asked to complete the questionnaires/survey at home, it is possible they may have been concerned that their parents or others could have seen what they were writing, unlike if they had all completed the questionnaires while sitting in the class room with peers, teachers and researchers some distance away. This may have impacted on their willingness to report family violence or NSSI behaviours. It may be prudent when conducting research into NSSI in the future to ensure that a confidential testing environment is provided. Additionally, NSSI disorder is included as a condition for further study in the current Diagnostic and Statistical Manual of Mental Disorders (DSM: American Psychological Association, 2013). We suggest that measures assessing the six diagnostic criteria proposed by the DSM should be included in future research. These include examining whether the person has engaged in NSSI on at least five days in the preceding 12-month period and the number of days in which NSSI episodes have occurred.

\section{Conclusions}

In conclusion, high rates of NSSI were found in this large sample of Vietnamese adolescents. This finding demonstrates the pressing need for the development of interventions to reduce this significant public health issue. Strategies that promote positive mental health and reduce 
symptoms of depression, anxiety and stress as well as approaches that help adolescents manage their internal emotions are also likely to be beneficial.

\section{Abbreviations}

DASS, Depression Anxiety Stress Scale; FASM, Functional Assessment of Self-Mutilation; HCMC, Ho Chi Minh City; NSSI, non-suicidal self-injury; SAVY, Survey Assessment of Vietnamese Youth.

\section{Ethical Approval}

All procedures performed in studies involving human participants were in accordance with the ethical standards of the Research Ethics Committee at the University of Medicine and Pharmacy at Ho Chi Minh City, Vietnam (No: 136/DHYD-HDDD) and with the 1964 Helsinki declaration and its later amendments or comparable ethical standards.

\section{Informed Consent}

Informed consent was obtained from all individual participants included in the study.

\section{Acknowledgments}

The authors would like to thank the director board at high schools participated in this study for their support during the study and all students who participated in this study.

\section{Funding}

This study received no funding.

\section{Disclosure}

The authors declare that they have no conflicts of interest for this work.

\section{References}

1. Ammerman BA, Jacobucci R, Kleiman EM, Muehlenkamp JJ, McCloskey MS. Development and validation of empirically derived frequency criteria for NSSI disorder using exploratory data mining. Psychol Assess. 2017;29(2):221-231. doi:10.1037/pas0000334

2. Lloyd EE, Kelley ML, Hope T. Self-mutilation in a community sample of adolescents: descriptive characteristics and provisional prevalence rates; 1997.

3. Annarosa C, Stefania C, Paolo C. Nonsuicidal self-injury: a systematic review. Front Psychol. 2017;8. doi:10.3389/fpsyg.2017.01946

4. Klonsky ED, Oltmanns TF, Turkheimer E. Deliberate self-harm in a nonclinical population: prevalence and psychological correlates. Am J Psychiatry. 2003;160(8):1501-1508. doi:10.1176/appi.ajp.160.8. 1501

5. Brown RC, Plener PL. Non-suicidal self-injury in adolescence. Curr Psychiatry Rep. 2017;19(3):20. doi:10.1007/s11920-017-0767-9
6. Swannell SV, Martin GE, Page A, Hasking P, St John NJ. Prevalence of nonsuicidal self-injury in nonclinical samples: systematic review, meta-analysis and meta-regression. Suicide Life Threat Behav. 2014;44(3):273-303. doi:10.1111/sltb.12070

7. Giletta M, Scholte RHJ, Engels RCME, Ciairano S, Prinstein MJ. Adolescent non-suicidal self-injury: a cross-national study of community samples from Italy, the Netherlands and the United States. Psychiatry Res. 2012;197(1-2):66-72. doi:10.1016/j.psychres.2012. 02.009

8. Guan K, Fox KR, Prinstein MJ. Nonsuicidal self-injury as a time-invariant predictor of adolescent suicide ideation and attempts in a diverse community sample. J Consult Clin Psychol. 2012;80 (5):842-849. doi:10.1037/a0029429

9. Yuan SNV, Kwok KHR, Ougrin D. Treatment engagement in specific psychological treatment vs. treatment as usual for adolescents with self-harm: systematic review and meta-analysis. Front Psychol. 2019;10:104. doi:10.3389/fpsyg.2019.00104

10. Barrocas AL, Giletta M, Hankin BL, Prinstein MJ, Abela JR. Nonsuicidal self-injury in adolescence: longitudinal course, trajectories, and intrapersonal predictors. J Abnorm Child Psychol. 2015;43 (2):369-380. doi:10.1007/s10802-014-9895-4

11. Brunner R, Kaess M, Parzer P, et al. Life-time prevalence and psychosocial correlates of adolescent direct self-injurious behavior: a comparative study of findings in 11 European countries. $J$ Child Psychol Psychiatry. 2014;55(4):337-348. doi:10.1111/jcpp.12166

12. American Psychiatric Association. Diagnostic and Statistical Manual of Mental Disorders. 5th ed. American Psychiatric Association; 2013.

13. Valencia-Agudo F, Burcher GC, Ezpeleta L, Kramer T. Nonsuicidal self-injury in community adolescents: a systematic review of prospective predictors, mediators and moderators. $J$ Adolesc. 2018;65:25-38. doi:10.1016/j.adolescence.2018.02.012

14. Kokaliari ED, Roy AW, Koutra K. A cross-sectional study comparing predictors of non-suicidal self-injury among college students in the United States and Greece. Int J Cult Ment Health. 2017;10(1):50-61. doi:10.1080/17542863.2016.1259339

15. Whitlock J. Self-injurious behavior in adolescents. PLoS Med. 2010;7 (5):e1000240-e1000240. doi:10.1371/journal.pmed.1000240

16. Tan AC, Rehfuss MC, Suarez EC, Parks-Savage A. Nonsuicidal self-injury in an adolescent population in Singapore. Clin Child Psychol Psychiatry. 2012;19(1):58-76. doi:10.1177/1359104512467273

17. Jung KY, Kim T, Hwang SY, et al. Deliberate Self-harm among young people begins to increase at the very early age: a nationwide study. J Korean Med Sci. 2018;33(30):e191. doi:10.3346/jkms.20 18.33.e191

18. Lang J, Yao Y. Prevalence of nonsuicidal self-injury in Chinese middle school and high school students: a meta-analysis. Medicine. 2018;97(42):e12916. doi:10.1097/MD.0000000000012916

19. Huynh VS. Studying the self-destructive behavior - A research direction that needs more concerns in schools. $J$ Sci. 2017;14(10):179.

20. Le MT, Nguyen HT, Tran TD, Fisher JR. Experience of low mood and suicidal behaviors among adolescents in Vietnam: findings from two national population-based surveys. $J$ Adolesc Health. 2012;51 (4):339-348. doi:10.1016/j.jadohealth.2011.12.027

21. General Statistics Office of Vietnam. Preliminary result of Vietnam population and housing census 2019. Available from: https://www. gso.gov.vn/default_en.aspx?tabid=515\&idmid=5\&ItemID=19281. Accessed November 19, 2021.

22. Lovibond SH, Lovibond PF. Manual for the Depression Anxiety Stress Scales. 2nd ed. Psychology Foundation of Australia; 1995.

23. Tran DT. Validation of the depression anxiety stress scales (DASS) 21 as a screening instrument for depression and anxiety in a rural community-based cohort of northern Vietnamese women. BMC Psychiatr. 2013;13(24). doi:10.1186/1471-244X-13-24

24. Nock MK, Prinstein MJ. A functional approach to the assessment of self-mutilative behavior. $J$ Consult Clin Psychol. 2004;72 (5):885-890. doi:10.1037/0022-006X.72.5.885 
25. Wang D, Zhang W, Bakhai A. Comparison of Bayesian model averaging and stepwise methods for model selection in logistic regression. Stat Med. 2004;23(22):3451-3467. doi:10.1002/sim.1930

26. You J, Leung F, Fu K, Lai CM. The prevalence of nonsuicidal self-injury and different subgroups of self-injurers in Chinese adolescents. Arch Suicide Res. 2011;15(1):75-86. doi:10.1080/ 13811118.2011.540211

27. Wong JP, Stewart SM, Ho SY, Lam TH. Risk factors associated with suicide attempts and other self-injury among Hong Kong adolescents. Suicide Life Threat Behav. 2007;37(4):453-466. doi:10.1521/ suli.2007.37.4.453

28. Lloyd-Richardson EE, Perrine N, Dierker L, Kelley ML. Characteristics and functions of non-suicidal self-injury in a community sample of adolescents. Psychol Med. 2007;37 (8):1183-1192. doi:10.1017/S003329170700027X

29. Lloyd-Richardson EE, Nock MK, Prinstein MJ. Functions of Adolescent Nonsuicidal Self-Injury. Routledge/Taylor \& Francis Group; 2009.
30. Turner BJ, Austin SB, Chapman AL. Treating nonsuicidal self-injury: a systematic review of psychological and pharmacological interventions. Can J Psychiatry. 2014;59(11):576-585. doi:10.1177/ 070674371405901103

31. Nguyen D, Dedding C, Pham T, Wright P, Bunders J. Depression, anxiety, and suicidal ideation among Vietnamese secondary school students and proposed solutions: a cross-sectional study. BMC Public Health. 2013;13(1):1195. doi:10.1186/1471-2458-13-1195

32. Nguyen HT, Dunne MP, Le AV. Multiple types of child maltreatment and adolescent mental health in Viet Nam. Research Support, NonU.S. Gov't. Bull World Health Organ. 2010;88(1):22-30. doi:10.2471/BLT.08.060061

33. Ong SH, Tan ACY, Liang WZ. Functions of nonsuicidal self-injury in Singapore adolescents: implications for intervention. Asian J Psychiatr. 2017;28:47-50. doi:10.1016/j.ajp.2017.03.015
Psychology Research and Behavior Management

\section{Publish your work in this journal}

Psychology Research and Behavior Management is an international, peer-reviewed, open access journal focusing on the science of psychology and its application in behavior management to develop improved outcomes in the clinical, educational, sports and business arenas. Specific topics covered in the journal include: Neuroscience, memory and decision making; Behavior modification and management; Clinical

\section{Dovepress}

applications; Business and sports performance management; Social and developmental studies; Animal studies. The manuscript management system is completely online and includes a very quick and fair peer-review system, which is all easy to use. Visit http://www. dovepress.com/testimonials.php to read real quotes from published authors. 